Fertility regulation during human lactation

\title{
WHO COLLABORATIVE STUDIES ON BREASTFEEDING
}

\author{
M. CARBALLO \\ Maternal and Child Health Unit, World Health Organization, Geneva
}

It is generally acknowledged that the popularity of breast-feeding, expressed in terms of the frequency with which it is taken up, and the length of time it is continued, is declining, and that, especially among populations of the Third World, the implications of this decline for infant health are likely to be serious and far reaching.

The current trend, however, is not a new phenomenon; in what are now highly industrialized societies, the practice of early weaning and reliance upon breast milk substitutes is by now a well-established fact of contemporary child-rearing behaviour, even though there are signs of a reverse trend among certain socioeconomic groups (Petros-Barvazian, 1975). A number of critical factors can be identified as having possibly contributed to the process of change in industrialized countries. The emergence of a large, gainfully employed, female labour force, and highly regimented work routines that increasingly drew women out of traditional frameworks of family life and maternal roles, was probably one of the more significant forces. Nuclearization of the family and the consequent erosion of inter-generational education and support systems, that had previously helped to maintain and facilitate breast-feeding, no doubt did much to weaken still further traditional child-rearing and feeding practices.

Whether the growth of an infant food industry that was able to achieve the elimination of pathogenic bacteria from cows milk, fortify milk products and approximate them to the composition of human milk, was a prime mover in this sequence of events or whether it was simply a resultant technology that developed to meet a need, is debatable, but certainly the widening availability of artificial infant foods in these settings and the emergence of the food industry as a strong marketing force must inevitably be viewed as one of the factors that has contributed to the continued decline in breast-feeding.

The changes that took place in infant feeding and child-rearing during the first half of this century, did not entirely escape attention at the time of their occurrence and some degree of concern was voiced for the significance of the trend represented for health and future patterns of infant growth and development. (Bain, 1948; Herlitz, 1947; Douglas, 1950). On the whole, concern by health personnel and action to prevent the trend appear to have been relatively muted, and this is probably due to the fact that broad socio-economic changes were taking place contemporaneously with the decline in breast-feeding and these were in turn 
being reflected in better overall levels of public health. Improved availability of health services in industrial/urban societies played a significant role in reducing infant mortality, and the introduction of better water supply and sanitation systems combined effectively with improved education, better nutrition and generally lower parity to produce a healthy environment in which the potentially harmful effects of the decline in breast-feeding tended to be attenuated.

In much of the developing world, however, the same mitigating conditions do not obtain. The complex of malnutrition, susceptibility to frequent infections and unregulated fertility, continues to characterize the health profile of most underprivileged populations of the Third World, and this is invariably compounded by limited health services coverage and few opportunities for short-term local socioeconomic development of the type that would contribute to a better health environment.

Against backgrounds such as these, the importance of breast milk and breastfeeding is accentuated. For not only does it constitute the most reliable and readily accessible source of nutrition appropriate for young infants, and a valuable agent of immunological defence against many childhood diseases, but it also constitutes the infant nutrition resource most economically compatible with many domestic and national capabilities. Puffer \& Serrano (1973) and Plank \& Milanesi (1973) have demonstrated the significance of different breast-feeding practices with respect to relative survival rates of infants in Latin American countries, and highlighted the role of appropriate breast-feeding in infant health (Text-figs 1-3).

In terms of both maternal as well as infant health, moreover, the potential role of prolonged lactation amenorrhoea as a child spacing mechanism should not be underestimated. Although on an individual basis it may not offer complete protection against conception, its value from the broad public health standpoint, is a

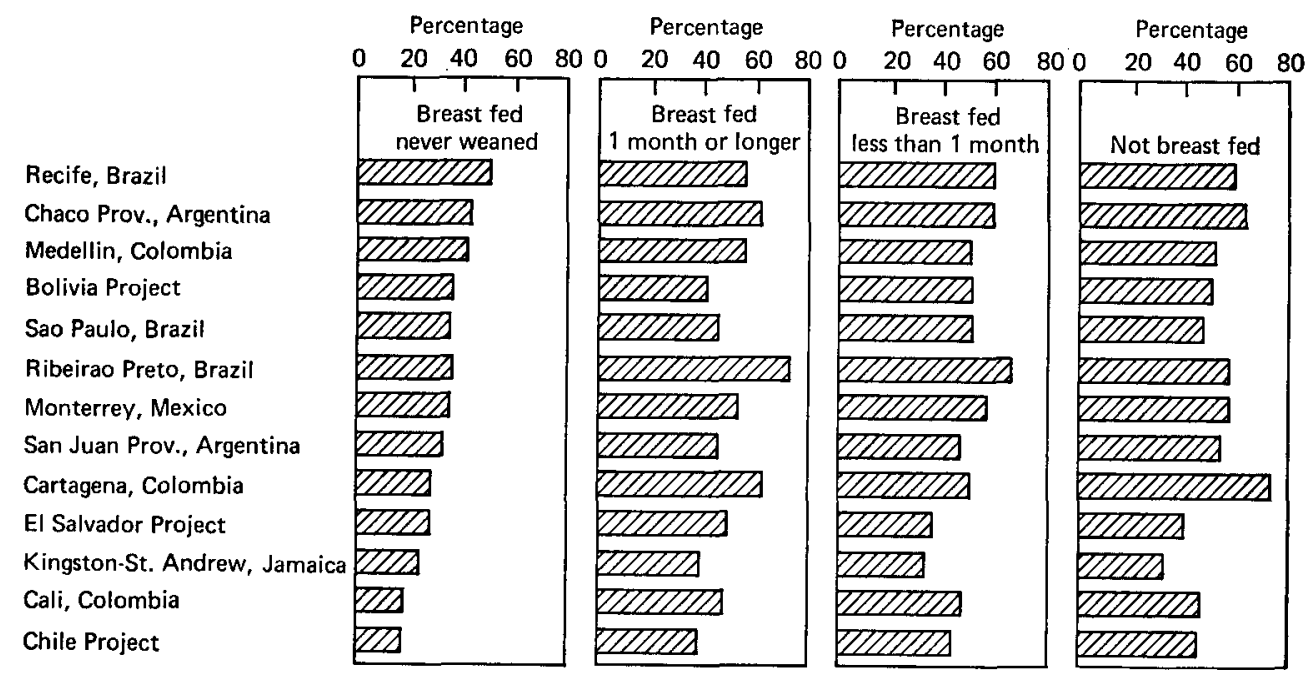

Text-fig. 1. Percentages of infants dying at 28 days to 5 months from nutritional deficiency as underlying or associated cause, according to type of feeding, in 13 study projects in Latin America (Puffer \& Serrano, 1973). 




Text-fig. 2. Percentages of infants dying at 6-11 months from nutritional deficiency as underlying or associated cause, according to type of feeding, in 13 study projects in Latin America (Puffer \& Serrano, 1973); b= insufficient numbers.

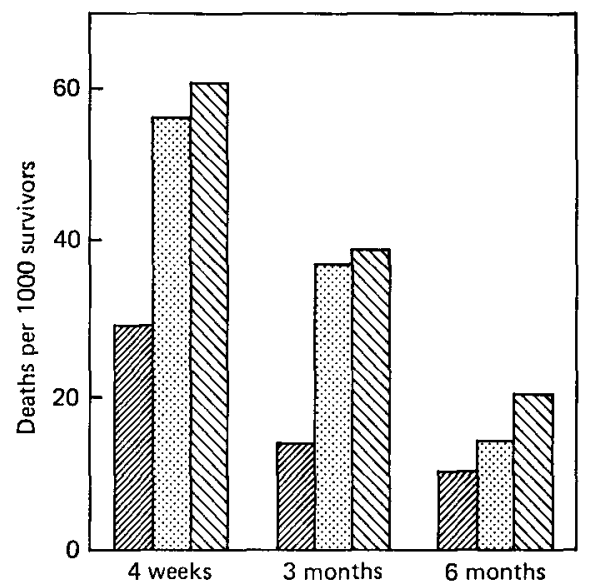

Text-fig. 3. Mortality rates in the first year of life among infants surviving at 4 weeks and at 3 and 6 months, by type of feeding, for rural Chile, 1969-70; breast-feeding only, 娄; breast-feeding plus bottle-feeding, :::; bottle-feeding only, (Plank \& Milanesi, 1973).

significant one, especially in settings where alternative family planning approaches are likely to be limited or, for socio-cultural reasons, unacceptable (Osteria, 1973; Rosa, 1975; Schaefer, 1971; Van Ginneken, 1974; Berman, Hanson \& Hellman, 1972).

Particularly then, although not exclusively in areas of the developing world where there are indications of an existing or potential erosion of breast-feeding, 
action is required to control the decline and encourage the practice of breastfeeding. Mothers and mothers-to-be especially, need to be correctly informed about the different alternatives of infant nutrition and the implications they may present for infant health and growth and development. Policy makers and healthrelated personnel similarly need to be aware of the relative health and economic values of breast-feeding.

In order that educational and promotional activities be effective in this regard, the initial requirement is that they be based on reliable data that reflect country and regional situations, the conditions and backgrounds of the different populations and the factors effecting changes among them. Reliable comparative data, however, are often lacking. Although the literature is replete with reports on breastfeeding and apparent trends towards early weaning, many of the reports currently available are anecdotal or tend to be based on observations of small and often highly selective groups of mothers. Accurate assessments of the veracity of these trends, or their magnitude, is thus difficult. Similarly the role played by different cultural, social, economic and psychological variables in emerging infant feeding practices remains relatively unclear even though their delineation is critical to the development of educational programmes on infant nutrition.

Any formulation and application of infant nutrition guide-lines at the country level, will equally require that more be known about lactation and the volume and composition of breast milk in mothers from different ecological settings and the effect a new pregnancy and different life styles might have on this. Again, little comparative information is available on this subject, most studies having been conducted on small and often highly selective groups.

The WHO Collaborative Studies on Breastfeeding which were implemented in 1975 have focused on these key issues (Text-fig. 4). Three operational phases of research and action have been outlined and a network of collaborating centres set

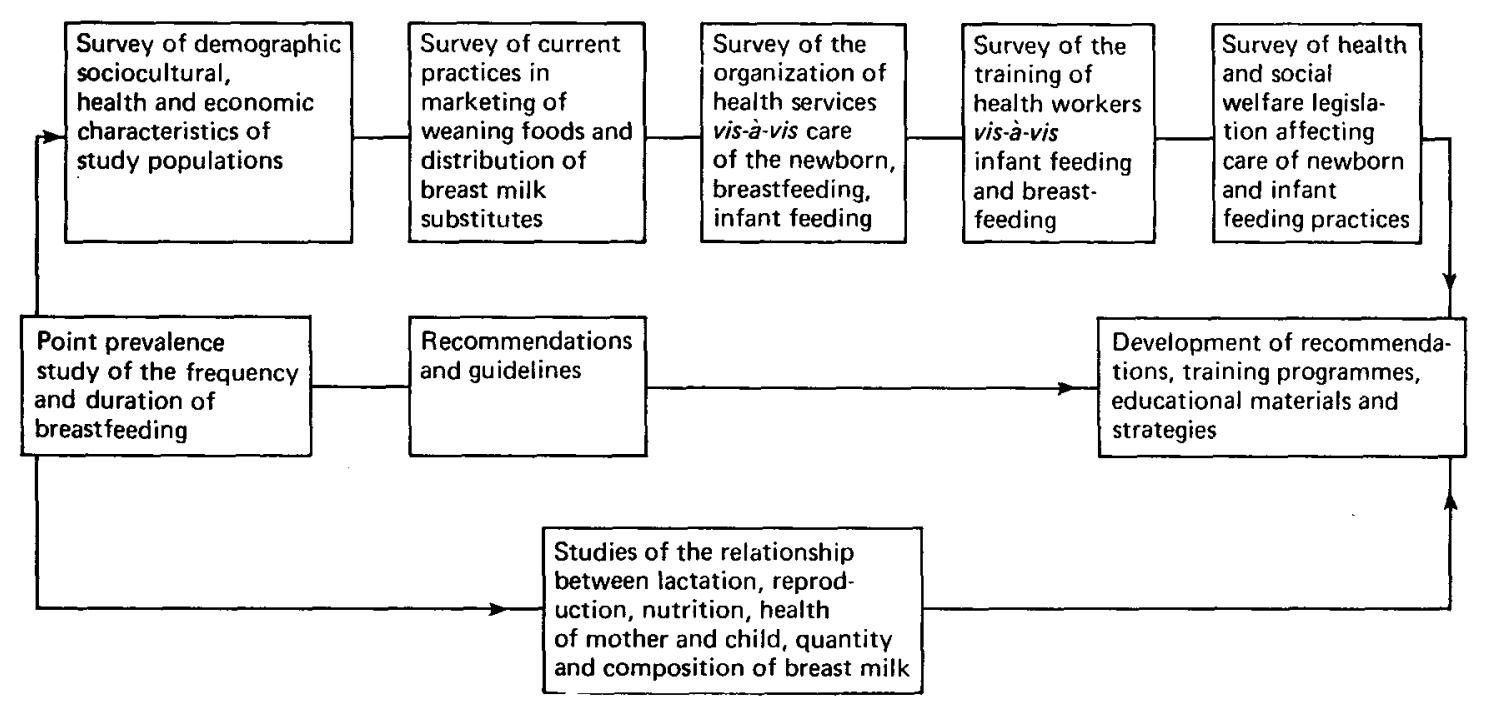

Text-fig. 4. WHO Collaborative Studies on Breastfeeding. 
up in the nine countries brought together to participate in their development and implementation.

Phase I of the programme involves a study of the frequency and duration of breast-feeding and the principal factors that influence it, the objective being to define current trends in breast-feeding and in so doing, identify those areas and population groups where changing feeding practices may pose a threat to infant health. Data on health and demographic background, infant nutrition behaviour and attitudes, and family planning practices have been gathered on mother/child pairs in each of three socio-economic groups-urban elite, urban poor and rural traditional, in the nine countries.

Complementing this basic study are five surveys undertaken in each participating country; the first is a survey of the sociocultural, demographic, health and economic characteristics of the populations in question and is designed to provide an overall view of the salient features of the social groups being studied and, in particular, the background against which changes in feeding practices can be assessed.

The remaining four surveys are addressed to what have been identified as key issues in the determination of breast-feeding patterns. Thus, the second survey concerns the current marketing practices and philosophies of infant food companies and pays specific attention to the types of potential markets being identified by industry and the advertising methods being used in these areas. It also reviews the distribution practices followed in nationally or internationally organized food programmes and the types of population groups served through these operations.

A third survey deals with the manner in which maternity and infant health services are organized with respect to facilitating the establishment and maintenance of breast-feeding. Rooming-in procedures in hospitals and health centres, pre- and post-natal counselling on infant nutrition and care, as well as health service policies with regard to infant feeding and distribution of infant foods are some of the topics covered.

While not systematically documented, it is widely felt that the decline in breastfeeding has in great part been due to the fact that health-related personnel, essentially in the most favourable position to influence mothers' attitudes on infant feeding behaviour, are themselves often insensitive to the need for mothers to be encouraged to breast-feed. The fourth survey then, is meant to review how and to what extent health personnel are trained in infant nutrition, particularly, in the needs for and of breast-feeding, and to what extent the responsibility for promoting specific feeding practices is seen as a health personnel function.

A fifth survey reviews health and social legislation and is predicated on the recognition that, for breast-feeding to be effectively practised, health and social legislation to protect and assist the mother during the lactation period are increasingly required. Provision of maternity benefits, allowances and other facilities are issues critical to this early stage of child-rearing, as is legislation on such issues as the provision of creches and breast-feeding breaks in industry.

Phase II of the programme focuses on the question of volume and composition of breast milk of mothers in the three population study groups included in the basic study. Maternal health is assessed and related to the quantity and quality of 
milk, type of feeding schedule followed and the health of the infant being breastfed. The relationship of lactation to amenorrhoea and the effect of a new pregnancy on lactation are also assessed. Two stages are proposed for this second phase; the first involves a cross-sectional study, which is already under way, and the second a longitudinal study that will gather additional information on continued nutrition behaviour and patterns of growth and development in the infant, and reproductive life of the mother.

One of the main purposes of Phases I and II is to provide the type of information that would be required for the development of guide-lines, educational materials and educational/promotional strategies involved in a programme designed to encourage breast-feeding. With respect to this, a variety of key 'audience' groups have been identified; for example, from the point of view of evolving social support systems that will help to facilitate breast-feeding, policy makers and legislators, health workers, husbands and industry will be focal points. Mothers and mothers-to-be will also be provided with specific information on the nutritional and health-related characteristics of different infant feeding approaches. Materials will similarly be prepared for health-related workers and will be designed to make them sensitive to the different social and economic, as well as physiological, aspects of breast-feeding, and to promote their involvement in its active encouragement.

Each of the audience groups, as well as others that are to be involved at later stages, will necessitate messages that differ in both content and mode of presentation. To assist in the development and implementation of these different materials and approaches, a series of short additional attitude and knowledge studies will be undertaken among these groups in the same settings as are involved in the basic study and the studies of volume and composition of breast milk.

On the basis of these activities and given the already increasing public awareness of the problem, it is anticipated that meaningful interventions in infant nutrition practices will be possible and that recent trends towards a marked decline in breast-feeding will, wherever appropriate, be able to be corrected.

\section{Discussion}

Harfouche: Are there any preliminary results from the studies?

Carballo: So far only from the Swedish study. What appears to be emerging is that breast-feeding is being practised more widely and for longer than had been originally anticipated; a significant percentage of the mothers included in the study, for example, continue breast-feeding for up to six months, which is perhaps unusual for a highly industrialized society and may indicate something of a reverse trend in breast-feeding behaviour.

Although the data collection phase is now complete in all the countries participating in the study, analysis has not been started on any data other than those from Sweden.

Van Ginneken: Is the analysis being done peripherally or centrally?

Carballo: Because computer facilities were not readily available in all the collaborating centres, it was decided to undertake the analysis centrally in Geneva. 
Thomson: From an analytical point of view, this is a formidable undertaking. The amount of paper generated is extraordinary. Getting the material reasonably clean, then de-bugging the programmes is a vast task. As usual, even in WHO research projects, it is much easier to mount an investigation than to make adequate provision for speedy analysis of the resulting data. Yet we have been mildly surprised that the difficulty has not been as great as we expected.

\section{References}

BaIN, K. (1948) The incidence of breast-feeding in hospitals in the United States. Pediatrics, 2, 313.

Berman, M.L., Hanson, K. \& Hellman, I.L. (1972) Effect of breast-feeding on post-partum menstruation, ovulation and pregnancy in Alaskan Eskimoes. Am. J. Obstet. Gynec. 114, 524.

Douglas, J.W.B. (1950) The extent of breast-feeding in the United Kingdom in 1946 with special reference to the health and survival of children. J. Obstet. Gynaec. Br. Commonw. 57, 355.

Herlitz, G. (1947) The duration of the period of lactation. Acta paediat. Stockh. 34, 234.

Osteria, T. (1973) Lactation and post-partum amenorrhoea in a rural community. Acta med. philipp. 9, 144.

Petros-Barvazian, A. (1975) Maternal and child health and breast-feeding. In: Modern Problems in Paediatrics, Vol. 15, p. 155. Karger, Basle.

Plank, S.S. \& Milanesi, M.L. (1973) Infant feeding and infant mortality in Chile. Bull. Wld Hlth Org. 48, 203.

Puffer, R.R. \& Serrano, C.V. (1973) Patterns of Mortality in Childhood. Pan American Health Organization Scientific Publication No. 262. Washington, DC.

Rosa, T.W. (1975) The Role of Breast-feeding in Family Planning. Protein Advisory Group Bulletin, UN, New York.

SchaEFER, O. (1971) When the Eskimo comes to town. Nutr. Today, 6, 8.

Van Ginneken, J.K. (1974) Prolonged breast-feeding as a birth spacing method. Stud. Fam. Plann. 5, 201. 